\title{
Portal hypertension in acute liver failure
}

\author{
M Navasa, J C Garcia-Pagán, J Bosch, J R Riera, R Bañares, A Mas, M Bruguera, J Rodés
}

Liver Unit, Hospital

Clinic i Provincial,

University of Barcelona

and Hospital Valle del

Nalon, Riaño-Langreo,

Asturias, Spain

M Navasa

J C Garcia-Pagán

J Bosch

J R Riera

R Bañares

A Mas

M Bruguera

J Rodés

Correspondence to:

J Bosch, Hepatic

Hemodynamic Laboratory,

Hemodynamic Laboratory,
Liver Unit, Hospital Clinic i

Previncial, Villaroel 170, Provincial, Villaroel 170,
08036 Barcelona, Spain.

Accepted for publication 21 October 1991

\begin{abstract}
Twenty five patients with acute liver failure were measured for hepatic venous pressure gradient as an index of portal pressure during the course of a transjugular liver biopsy. Hepatic venous pressure gradient ranged from 4 to $24.5 \mathrm{~mm} \mathrm{Hg}$ with a mean of $12.8(5.3) \mathrm{mm}$ $\mathrm{Hg}$ (normal values $<5 \mathrm{~mm} \mathrm{Hg}$ ). All patients but one had increased portal pressure gradient. Portal hypertension correlated with the degree of architectural distortion of the liver, as suggested by a direct correlation between hepatic venous pressure gradient and the area of reticulin collapse, evaluated by means of a morphometric analysis on Sirius red stained liver slides $(r=0.43, p<0.05)$. Hepatic venous pressure gradient was significantly higher in patients with ascites $(15 \cdot 1$ (5) $\mathrm{mm} \mathrm{Hg}, \mathrm{n}=15$ ) or renal failure $(14.4(5.3) \mathrm{mm} \mathrm{Hg}, \mathrm{n}=16)$ than in those without $(9.3(3.4) \mathrm{mm} \mathrm{Hg}$ and 10.1 (4) $\mathrm{mm}$ $\mathrm{Hg}$, respectively; $\mathrm{p}<0.05$ ). Portal hypertension was associated with systemic vasodilation and a hyperkinetic circulatory state, with decreased arterial pressure, and peripheral resistance and increased cardiac output.
\end{abstract}

Fulminant hepatic failure is a syndrome characterised by short term development of signs of advanced liver failure leading to hepatic encephalopathy in the absence of previous liver disease.' Fulminant hepatic failure has a very high mortality, especially when caused by acute viral hepatitis, which is the most common cause of this syndrome. ${ }^{12}$ Over half of the patients exhibit clinical signs associated with portal hypertension, such as ascites and hepatorenal syndrome ${ }^{34}$ It has been suggested that portal hypertension could be caused by an increased hepatic resistance to portal blood flow, as a consequence of sinusoidal collapse and distortion of liver architecture after extensive liver cell necrosis. ${ }^{35}$

Transjugular liver biopsy allows histological and haemodynamic studies to be carried out during the course of fulminant hepatic failure. ${ }^{6}$ This allows better characterisation of portal hypertension and the examination of the relationship between portal pressure, presence of ascites and renal failure, and the extent of histological damage. This study presents our findings in a series of 25 consecutive patients.

\section{Methods}

\section{PATIENTS}

The study was carried out in 25 patients with acute liver failure admitted to the Liver Intensive Care Unit during a three year period. Fifteen patients were male and 10 female, with an age ranging from 14 to 62 years (mean (SD) 34 (15) years) (Table). The aetiology of liver failure was assessed by clinical history, and by serologic markers of hepatitis B, hepatitis delta, and hepatitis A. The possibility of Wilson's disease presenting as fulminant hepatic failure was investigated in all patients by measuring plasma and urine copper and plasma ceruloplasmin concentrations.

The diagnosis of acute liver failure was based on the accepted clinical criteria: development of

Clinical data of the 25 patients studied

\begin{tabular}{|c|c|c|c|c|c|c|c|c|c|c|c|}
\hline $\begin{array}{l}\text { Patient } \\
\text { no }\end{array}$ & $\begin{array}{l}\text { Age } \\
(y r)\end{array}$ & $\begin{array}{l}\text { Sex } \\
M / F\end{array}$ & Aetiology & $F u l / S u b$ & $\begin{array}{l}\text { Enc } \\
\text { (grade) }\end{array}$ & Ascites & $\begin{array}{l}\text { Creat } \\
(\mu \mathrm{mol} / \mathrm{l})\end{array}$ & $\begin{array}{l}H V P G \\
(m m H g)\end{array}$ & $\begin{array}{l}C O \\
(l / \min /)\end{array}$ & $\begin{array}{l}\text { SVR } \\
\left(\text { dyn } / \mathrm{s} . \mathrm{cm}^{-5}\right)\end{array}$ & Death \\
\hline 1 & 40 & $M$ & D & Sub & IV & Yes & 230 & 20.5 & 4 & 1800 & Yes \\
\hline 2 & 16 & $\mathrm{~F}$ & D & Ful & II & No & 71 & 8 & - & - & No \\
\hline 3 & 39 & M & nAnB & Ful & III & No & 177 & 11 & - & - & Yes \\
\hline 4 & 27 & M & $\mathrm{nAnB}$ & Sub & IV & Yes & 265 & 22 & $7 \cdot 5$ & 938 & Yes \\
\hline 5 & 41 & M & B & Sub & IV & Yes & 972 & 16 & 8.9 & 952 & Yes \\
\hline 6 & 51 & M & nAnB & Sub & IV & Yes & 804 & 14 & - & - & Yes \\
\hline 7 & 24 & M & nAnB & Ful & IV & No & 221 & 6.5 & 13 & 369 & Yes \\
\hline 8 & 22 & $M$ & D & Sub & IV & No & 53 & $12 \cdot 5$ & - & - & No \\
\hline 9 & 55 & $\mathrm{~F}$ & Haloth & Sub & II & Yes & 53 & 12 & $8 \cdot 1$ & 829 & No \\
\hline 10 & 62 & M & A & Ful & IV & Yes & 946 & 7 & $8 \cdot 2$ & 829 & Yes \\
\hline 11 & 27 & $\mathrm{~F}$ & D & Sub & IV & Yes & 354 & 14 & - & - & Yes \\
\hline 12 & 22 & M & B & Ful & IV & No & 35 & 8 & - & - & No \\
\hline 13 & 52 & $\mathrm{~F}$ & nAnB & Sub & IV & No & 318 & 7 & $6 \cdot 3$ & 977 & Yes \\
\hline 14 & 51 & $\mathbf{F}$ & nAnB & Sub & IV & Yes & 557 & $24 \cdot 5$ & 6.4 & 1375 & Yes \\
\hline 15 & 23 & $\mathrm{~F}$ & D & Sub & IV & Yes & 97 & 9 & - & - & Yes \\
\hline 16 & 62 & M & B & Sub & IV & Yes & 610 & 18 & - & - & Yes \\
\hline 17 & 42 & $\mathrm{~F}$ & nAnB & Sub & IV & No & 132 & 15 & - & - & Yes \\
\hline 18 & 21 & M & & Sub & II & Yes & 97 & 18 & - & - & No \\
\hline 19 & 24 & $\mathrm{~F}$ & B & Ful & II & No & 53 & $7 \cdot 5$ & - & - & No \\
\hline 20 & 23 & M & & Sub & IV & Yes & 919 & $16 \cdot 5$ & 6.5 & 1070 & Yes \\
\hline 21 & 14 & $\mathrm{~F}$ & $\mathrm{nAnB}$ & Sub & II & Yes & 132 & 12 & $6 \cdot 2$ & 1058 & No \\
\hline 22 & 25 & M & $\mathrm{nAnB}$ & Sub & IV & No & 857 & 13 & 13 & 363 & Yes \\
\hline 23 & 43 & M & & Ful & IV & Yes & 185 & 9 & - & - & Yes \\
\hline 24 & 21 & M & D & Ful & IV & Yes & 238 & 15 & $8 \cdot 4$ & 971 & No \\
\hline 25 & 26 & $\mathrm{~F}$ & $\bar{B}$ & Ful & IV & No & 132 & 4 & $5 \cdot 5$ & 1381 & Yes \\
\hline
\end{tabular}

Ful/Sub: fulminant/subfulminant; Enc: encephalopathy; Creat: creatinine; HVPG: hepatic venous pressure gradient; $\mathrm{CO}$ cardiac output; SVR: systemic vascular resistance; M/F: male/female; $D$ : virus delta hepatitis; nAnB: virus non-A non-B hepatitis; B: virus B hepatitis; Haloth: halothane hepatitis; A: virus A hepatitis. 
hepatic encephalopathy and fall in prothrombin index below $40 \%$ within eight weeks of the onset of symptoms in the absence of previous liver disease.' Patients were divided in two groups: (i) fulminant hepatic failure, when hepatic encephalopathy appeared in less than two weeks after the onset of jaundice, and (ii) subfulminant hepatic failure if hepatic encephalopathy complicated liver failure two to eight weeks after the onset of jaundice.

After admission, the patients were transferred to the Liver Intensive Care Unit. Physical examination including the presence or development of ascites and evaluation of neurological status were performed at least every four hours. All patients had continuous monitoring of arterial pressure and urine output. Biochemical analysis including standard liver and renal function tests, as performed daily until death or recovery. Renal failure was considered to be present when plasma creatinine increased above $132 \mu \mathrm{mol} / \mathrm{l}$.

Within 48 hours of admission, all patients underwent a haemodynamic study during transjugular liver biopsy. Briefly, under local anaesthesia a venous introducer (USCI International Inc, Mass, USA) was placed in the right internal jugular vein by the Seldinger technique, and the main right hepatic vein was catheterised under fluoroscopy using a $7 \mathrm{~F}$ balloon tipped catheter (Medi-Tech, Cooper Scientific Corp, Watertown, MA, USA); repeated measurements of wedged and free hepatic venous pressures were obtained by inflating and releasing the balloon. Portal pressure was estimated from the hepatic venous pressure gradient - that is, the difference between wedged hepatic venous pressure and free hepatic venous pressure. ' In 13 of these patients a Swan-Ganz catheter was inserted into the pulmonary artery for measurements of cardiopulmonary pressures and cardiac output (Edwards Laboratory, Los Angeles, CA, USA) (thermal dilution). Arterial pressure was monitored by sphygmomanometry (Dinamap, Critikon, Tampa, Florida, USA) and heart rate recorded by continuous electrocardiograph monitoring. Systemic vascular resistance (dyn/ sec. $\mathrm{cm}^{-5}$ ) was calculated as (MAP-RAP) ${ }^{\star 80 /}$ $\mathrm{CO}$, in which MAP is the mean arterial pressure, RAP is the right atrial pressure, and CO the cardiac output. All measurements were performed by triplicate and permanent tracings were obtained on a multichannel recorder (Hewlett Packard 7754B). After that, an $8 \mathrm{~F}$ catheter was introduced in the hepatic vein and a preshaped liver biopsy needle (Ingenor Medical, Paris, France) was slipped into the catheter and the transjugular liver biopsy was obtained in each patient using the standard technique. ${ }^{6}$ There were no complications from these procedures.

Liver biopsy specimens were sectioned serially and stained with haematoxylin and eosin, Masson's trichrome stain, and reticulin stain for conventional histological analysis. In addition, all specimens were stained with Sirius red F3BA in order to do a quantitative morphometric analysis of the reticulin collapse by means of an automatic image quantifier (Ramtek-9351), as previously described. ${ }^{89}$ The measurements were based on the contrast between dark (collapse) and light areas. Three consecutive liver areas were evaluated for each specimen by one of us, under blind conditions. The results were expressed as the mean percentage of Sirius red stained area of the section. The intra assay variability of the measurement was of $6 \%$.

\section{STATISTICAL ANALYSIS}

All values are reported as mean (SD). The Student's $t$ test, the $\chi^{2}$ test and the coeficient of correlation were used in the statistical analysis of the results. Statistical significance was established at $\mathrm{p}<0.05$.

\section{Results}

The mean time between the onset of clinical symptoms and the haemodynamic study was 21 days, with a range of six to 56 days. The course of liver failure was subfulminant in 16 patients $(64 \%)$ and fulminant in the remaining nine patients.

The aetiology of acute liver failure was viral hepatitis in all but one patients. Six patients had acute hepatitis B (24\%), eight acute delta infection (32\%), one had hepatitis A (4\%), one had halothane hepatitis and the remaining nine cases were considered as non-A-non-B hepatitis (36\%) (Table). Ascites was detected in 15 patients $(60 \%)$. The ascites had a low protein content $(14(6) \mathrm{g} / \mathrm{l})$. Renal failure developed in 16 (64\%).

As shown in the Table, hepatic venous pressure gradient ranged from 4 to $24.5 \mathrm{~mm} \mathrm{Hg}$ with a mean of $12.8(5.3) \mathrm{mm} \mathrm{Hg}$ (normal values $<5 \mathrm{~mm} \mathrm{Hg}$ ) (Fig 1). All patients but one had an increased hepatic venous pressure gradient. Fifteen patients $(60 \%)$ had a hepatic venous pressure gradient equal or greater than $12 \mathrm{~mm}$ $\mathrm{Hg}$, and were considered to have severe portal hypertension, while nine patients had minor degrees of portal hypertension (hepatic venous pressure gradient from 6 to $11 \mathrm{~mm} \mathrm{Hg}$ ). The 13 patients who had measurements of cardiac output, showed a hyperdynamic circulation manifested by a high cardiac output $(7 \cdot 8(2 \cdot 6) \mathrm{l} / \mathrm{min})$, and decreased mean arterial pressure $(89$ (16) $\mathrm{mm} \mathrm{Hg}$ ) and systemic vascular resistance (993 (387) dyn $/ \mathrm{sec} \mathrm{cm}^{-5}$ ).

Presence of ascites was related to the severity of portal hypertension. The hepatic venous pressure gradient was significantly higher in patients with ascites $(15 \cdot 1(5) \mathrm{mm} \mathrm{Hg}$ ) than in those without $(9.3(3.4) \mathrm{mm} \mathrm{Hg}),(\mathrm{p}<0.01)$. Moreover, among the 15 patients with ascites, 12 $(80 \%)$ had severe portal hypertension. On the contrary, only three of the 10 patients without ascites had an hepatic venous pressure gradient above $12 \mathrm{~mm} \mathrm{Hg}(\mathrm{p}<0.02)$.

Patients with renal failure had a higher hepatic venous pressure gradient than those without it $(14 \cdot 4(5 \cdot 3) \mathrm{mm} \mathrm{Hg} v 10 \cdot 1$ (4) $\mathrm{mm} \mathrm{Hg}$, respectively; $p<0.05)$. Renal failure was present in 11 of the 15 patients with an hepatic venous pressure gradient above $12 \mathrm{~mm} \mathrm{Hg}$.

The hepatic venous pressure gradient was significantly higher in patients with subfulminant hepatic failure $(15 \cdot 3(4 \cdot 6) \mathrm{mm} \mathrm{Hg})$ than in those with fulminant hepatic failure $(8 \cdot 4(3 \cdot 1)$ 


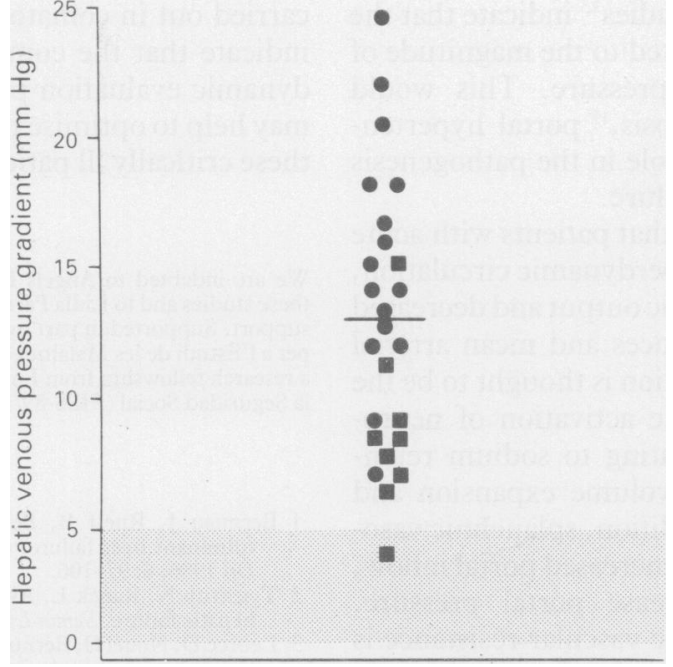

Figure 1: Individual values of the hepatic venous pressure gradient $(H V P G)$ in patients with acute liver failure. The horizontal line indicates the mean value of the whole series. Patients with fulminant liver failure are represented by squares, while those with subfulminant (over two weeks course) are represented by circles. Note that the latter had a greater HVPG than the former $(15 \cdot 3(4 \cdot 6)$ v $8 \cdot 4(3 \cdot 1) \mathrm{mm}$ $\mathrm{Hg}$, respectively). The shadowed area represent the normal
rang range.

$\mathrm{mm} \mathrm{Hg}, \mathrm{p}<0.001)$. Among the 16 patients with subfulminant hepatic failure, all but two $(87 \cdot 5 \%)$ had an hepatic venous pressure gradient above $12 \mathrm{~mm} \mathrm{Hg}$. This was only seen in one of the nine patients with fulminant hepatic failure $(p<0.001)$ (Table). Ascites was more common in patients with subfulminant hepatic failure than in patients with fulminant hepatic failure $(12 / 16$ $v$ three of nine patients, respectively, $\mathrm{p}=0.08$ ).

Reticulin collapse, measured by the percentage of the total area of the section stained by Sirius red averaged $15.7(8.4) \%$ (mean value in normal liver $3 \cdot 1(0 \cdot 5 \%) .{ }^{9}$ There was a direct correlation between the degree of reticulin collapse and the hepatic venous pressure gradient $(r=0.43, p<0.05)$ (Fig 2$)$.

There were no significant differences in the degree of collapse between patients with fulminant and subfulminant hepatic failure $(14 \cdot 6(9 \cdot 0)$ $v 16 \cdot 2(8 \cdot 3) \%, \mathrm{NS})$.

The whole mortality rate of the present series was $68 \%$. There were no significant differences in hepatic venous pressure gradient between patients who survived and those who did not $(11.6(3.7) v 13.3(5.9) \mathrm{mm} \mathrm{Hg}, \mathrm{NS})$. The area of reticulin collapse, however, was significantly lower in survivors $(9 \cdot 7(4 \cdot 7) v 18 \cdot 1(8 \cdot 3) \%$, $\mathrm{p}<0.02$ ).

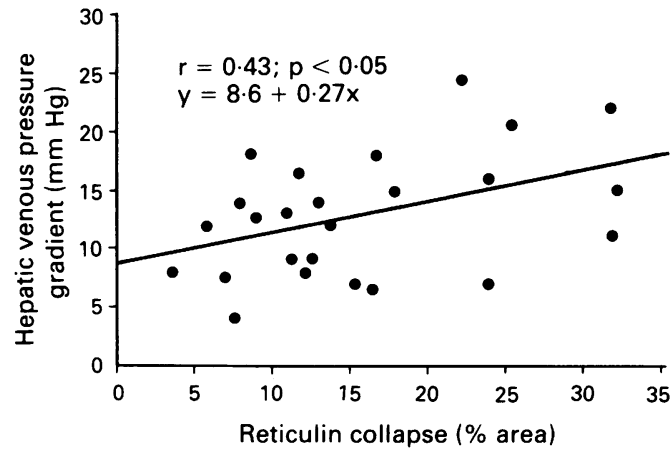

\section{Discussion}

Portal hypertension usually complicates the evolution of chronic liver diseases. ${ }^{10}$ Ascites and gastrointestinal bleeding caused by ruptured oesophageal varices are frequent consequences of severe portal hypertension. " It has been shown that the development of ascites is also common in acute liver failure, ${ }^{34}$ and has been related to the presence of severe portal hypertension. ${ }^{35}$ Previous studies from our unit, however, have shown that ascites may occur in patients with acute viral hepatitis in the absence of portal hypertension. ${ }^{12}$ These patients exhibited an 'exudative' ascites with a high protein and lymphocyte content and had a good prognosis. ${ }^{12}$

The present study further shows that portal hypertension is common in acute liver failure. In fact, all but one of the patients studied had a hepatic venous pressure gradient above the normal values, thus indicating intrahepatic sinusoidal portal hypertension. ${ }^{10}$ Although portal pressure is determined by the interrelationship of blood flow and vascular resistance, it is generally accepted that portal hypertension is initiated by an increased resistance to portal blood flow. ${ }^{1013}$ The site of increased resistance in patients with acute liver failure has not been clearly established. There is no evidence of sinusoidal fibrosis and nodular regeneration. ${ }^{14}$ Similarly, there is no massive infiltration of the liver, as happens in portal hypertension that may be associated with haematologic disorders or amyloidosis, ${ }^{15}$ nor evidence of obstruction at the hepatic outflow, as observed in venoocclusive disease.$^{16}$ Therefore, the most likely explanation for the increased hepatic venous pressure gradient is the extensive necrosis and subsequent reticulin collapse, that probably causes a severe distortion of the hepatic microcirculation. The direct correlation found in the present study between the degree of reticulin collapse and the hepatic venous pressure gradient, which is very similar to that obtained by Valla $e t a l^{5}$ in patients with acute viral hepatitis, further supports this hypothesis. The correlation between the area of reticulin collapse, however, and hepatic venous pressure gradient, although statistically significant, was poor. This may indicate that other factors also play an important role in increasing hepatic venous pressure gradient in acute liver failure. In addition, it is likely that morphometric analysis in the transjugular biopsies is subject to some degree of sampling error, which may obscure this relationship. Measurements of hepatic venous pressure gradient with the balloon occlusion technique, however, estimate the sinusoidal perfusion pressure in a relatively large area of the liver. ${ }^{17}$ It is therefore possible that measurements of hepatic venous pressure gradient provide a better estimate of the degree of architectural distortion in acute liver failure than morphometric analysis of liver biopsies. Nevertheless, the current finding of a statistically significant greater degree of reticulin collapse in patients who died than in the survivors clearly points out the important prognostic connotation of the severity of histological damage in patients with acute liver failure. ${ }^{18}$

The present study also shows a high prevalence of ascites in patients with acute liver failure. 
Our data and previous studies ${ }^{35}$ indicate that the presence of ascites is related to the magnitude of the increase in portal pressure. This would suggest that, as in cirrhosis, ${ }^{19}$ portal hypertension plays an important role in the pathogenesis of ascites in acute liver failure.

It is important to note that patients with acute liver failure showed a hyperdynamic circulation, evidenced by a high cardiac output and decreased systemic vascular resistances and mean arterial pressure. This vasodilatation is thought to be the mechanism triggering the activation of neurohumoral factors contributing to sodium retention, extracellular fluid volume expansion and ascites formation.$^{19}$ In addition, splanchnic vasodilation, which results in increased portal inflow, may contribute to increase portal pressure, specially when the hepatic vascular resistance is increased. ${ }^{10}$ The pathogenesis of systemic vasodilation remains largely conjectural. As suggested in patients with cirrhosis, it is likely to be of multifactorial origin. ${ }^{10} 19 \mathrm{~A}$ possible explanation is the accumulation of vasoactive substances of splanchnic origin in the systemic circulation that are either metabolised by the normal liver or abnormally released during acute liver failure. ${ }^{102021}$ In that regard it has been reported that increased levels of substance $P$ are observed in patients with advanced liver failure and that these correlate with the degree of hypotension. ${ }^{22}$ In addition, other factors such as endotoxaemia, sepsis, and fever may contribute to further exaggerate these circulatory abnormalities. ${ }^{21}$

Renal failure was common in the present series of patients with acute liver failure. Some of these patients had acute tubular necrosis, which may be related to shock, bacteraemia hypovolaemia and drug nephrotoxicity. Some patients, however, exhibited 'functional' renal failure, with many similarities observed in cirrhosis. As in this condition, ${ }^{23}$ functional renal failure in acute liver failure has been related to an imbalance between neurohumoral factors with renal vasoconstrictive activity and renal vasodilators. ${ }^{24}$ In this regard, increased plasma renin activity and decreased renal prostaglandin production have been reported in patients with acute liver failure. ${ }^{24}$ As already mentioned, activation of neurohumoral vasoactive factors is triggered by the extreme vasodilation frequently seen in these patients. ${ }^{19}$ Therefore, as in cirrhotics with hepatorenal syndrome, patients with acute liver and renal failure exhibit renal vasoconstriction in the context of marked systemic vasodilation. This indicates that there should be some areas where vasodilation is greater than others. Experimental data suggest that vasodilation predominates in the splanchnic territory. ${ }^{25}$ It is thus possible that if the splanchnic vasodilation could be overcome, there could be an amelioration in the systemic and renal circulation. ${ }^{26}$ This actually has been reported in patients with cirrhosis, ${ }^{27}$ Although there has not yet been a clinical or experimental study exploring this possibility in acute liver failure.

Finally, it should be emphasised that we had no complications in obtaining transjugular biopsies in patients with acute liver failure despite the severe coagulopathy inherent to this condition, even though these studies were frequently carried out in comatosed patients. Our findings indicate that the combined histological haemodynamic evaluation provided by this procedure may help to optimise the medical management of these critically ill patients.

We are indebted to Angels Baringo for his expert assistance in these studies and to Lidia París and Eulàlia Ventura for secretarial support. Supported in part by grants from the Fundació Catalan per a l'Estudi de les Malalties del Fetge. Dr J C Garcia-Pagán held a research fellowship from Fondo de Investigaciones Sanitarias de la Seguridad Social (FISS-89/1516).

1 Bernuau J, Rueff B, Benhamou JP. Fulminant and subfulminant liver failure: definitions and causes. Semin Liver Dis 1986; 6: 97-106.

2 Tygstrup N, Ranek L. Assessment of prognosis in fulminant hepatic failure. Semin Liver Dis 1986; 6: 129-37.

3 Lebrec D, Nouel O, Bernuau J, Rueff B, Benhamou JP. Portal hypertension in fulminant viral hepatitis. Gut 1980; 21: $962-4$

4 Navasa $M$, Panés J, Terés J, Bruguera $M$, Rodés J. Insuficiencia hepática aguda grave: análisis de 51 casos. Gastroenterol Hepatol 1986; 9: 221-7.

5 Valla D, Flejou JF, Lebrec D, Bernuau J, Rueff B, Salzmann $\mathrm{JL}$, et al. Portal hypertension and ascites in acute hepatitis: Clinical, hemodynamic and histological correlations. Hepatology 1989; 10: 482-7.

6 Lebrec D, Goldfarb G, Degott C, Rueff B, Benhamou JP. Transvenous liver biopsy. An experience based on 1000 hepatic tissue samplings with this procedure. Gastroenterology 1982; 83: 338-40.

7 Bosch J, Mastai R, Kravetz D, Navasa M, Rodés J. Hemodynamic evaluation of the patient with portal hypertension. Semin Liver Dis 1986; 6: 309-17.

8 Sweat F, Fuchtler H, Rosenthal SI. Sirius red F3BA as a stain for connective tissue. Arch Pathol 1964; 78: 69-72.

9 Rubio CA, Porwit A. Quantitation of fibrosis in liver biopsies. Anal Quant Cytol Histol 1988; 10: 107-9.

10 Bosch J, Navasa M, Garcia-Pagán JC, DeLacy AM, Rodés J. Portal Hypertension. Med Clin North Am 1989; 73: 931-53.

11 García-Tsao G, Groszmann RJ, Fisher RL, Conn H, Atterbury E, Glickman M. Portal pressure, presence of gastroesophageal varices and variceal bleeding. Hepatology gastroesophageal

12 Viola C, Vineta L, Bosch J, Rodés J. Exudative ascites in the course of acute type B hepatitis. Hepatology 1983; 3: 1013-5.

13 Sikuler E, Kravetz D, Groszmann RJ. Evolution of portal hypertension and mechanisms involved in its maintenance in a rat model. Am $\mathcal{F}$ P hysiol 1985; 248: G618-25.

14 Anthony PP, Oshak KG, Nayac NC. The morphology of cirrhosis. f Clin Pathol 1978; 31: 395-414.

15 Urbano A, Navasa M, Mont Ll, Bosch J, Bruguera M, Rodés J. Colestasis intrahepática e hipertensión portal en un paciente con amiloidosis primaria. Gastroenterol Hepatol 1986; 9: 186-8.

16 Kasturi TE, Manchanda SC, Tandon RK, Rajani M, Bathia ML. Haemodynamic studies in veno-occlusive disease of the liver. Br Heart f 1979; 41: 594-9.

17 Groszmann RJ, Glickman M, Blei AT, Storer E, Conn HO. Wedged and free hepatic venous pressure measured with a Wedged and free hepatic venous pressure measured
balloon catheter. Gastroenterology 1979; 76: 253-8.

18 Gazzard BG, Portmann B, Murray-Lyon IM, Williams R. Causes of death in fulminant hepatic failure and relationship to quantitative histological assessment of parenchimal damage. $Q \mathcal{F}$ Med 1975; 176: 615-26.

19 Schrier RW, Arroyo V, Bernardi M, Epstein M, Henriksen $\mathrm{JH}$, Rodés J. Peripheral arterial vasodilation hypothesis: a proposal for the initiation of renal sodium and wate retention in cirrhosis. Hepatology 1988; 8: 1151-7.

20 Bihari DJ, Gimson AES, Williams R. Cardiovascular, pulmonary and renal complications of fulminant hepatic failure. Semin Liver Dis 1986; 6: 119-28.

21 Trewby PN, Williams R. Pathophysiology of hypotension in patients with fulminant hepatic failure. Gut 1977; 18: patients

22 Hörtnagl $H$, Lochs $H$, Kleinberger G, Singer EA, Lenz K. Substance $P$ is markedly increased in plasma of patients with Substance $P$ is markedly increased in
hepatic coma. Lancet $1984 ; \mathrm{i}: 480-3$.

23 Ring-Larsen H, Henriksen JH. Pathogenesis of ascites formation and hepatorenal syndrome: Humoral and hemodynamic factors. Semin Liver Dis 1986; 6: 341-52.

24 Guarner F, Hughes RD, Gimson AES, Williams R. Renal function in fulminant hepatic failure: haemodynamics and renal prostaglandins. Gut 1987; 28: 1643-7.

25 Férnandez-Seara J, Prieto J, Quiroga J, Zozaya JM, Cobo MA, Rodriquétire JL et al. Systemic and regional hemodynamics in patients with liver cirrhosis and ascites with and without functional renal failure. Gastroenterology 1989; 97 1304-12.

26 Bosch J. Splanchnic vasodilation and renal vasoconstriction: A key to the hepatorenal syndrome? Hepatology 1990; 12 : 1445-7.

27 Lenz K, Hortnagle H, Druml W, Grimm G, Laggner A, Schneoweisz B, et al. Beneficial effect of 8-ornithin vasopressin on renal disfunction in decompensated cirrhosis. Gut 1989; 30: $90-6$. 